\title{
Behavioral Intervention versus Pharmacotherapy or Their Combinations in the Management of Overactive Bladder Dysfunction
}

\author{
Khanh Tran, Robert M. Levin, and Shaker A. Mousa \\ The Pharmaceutical Research Institute, Albany College of Pharmacy and Health Sciences, \\ Rensselaer, NY 12144, USA \\ Correspondence should be addressed to Shaker A. Mousa, shaker.mousa@acphs.edu
}

Received 7 July 2009; Accepted 7 November 2009

Recommended by William Lynch

\begin{abstract}
Overactive bladder syndrome (OAB) refers to individuals with the following symptoms: urinary urgency, increased urinary frequency, and urge incontinence. These symptoms are not life threatening but can cause embarrassment and significantly impact quality of life. There are numerous treatment options for OAB, including behavioral therapy, traditional pharmacological therapy or a combination of the two. These options are considered the mainstay of treatment for OAB. We carried out a comprehensive systematic review of the available literature on the effectiveness of behavioral intervention, anticholinergic drugs, and their combination in the management of adults with overactive bladder, with emphasis on results from clinical trials and primary literature. Each treatment intervention is efficacious, and the choice should be based on the patient's severity of symptoms, tolerability, compliance and satisfaction with the treatment. Based on available literature, management of OAB using a combination of behavioral therapy and drug intervention is the most efficacious in terms of patient satisfaction, perceived improvement, and reduction of bladder symptoms. It is also the most practical and cost effective for optimal management of patients with OAB. Pharmacological treatment, in addition to behavioral therapy, remains important in the management of adults with $\mathrm{OAB}$ syndrome.
\end{abstract}

Copyright (c) 2009 Khanh Tran et al. This is an open access article distributed under the Creative Commons Attribution License, which permits unrestricted use, distribution, and reproduction in any medium, provided the original work is properly cited.

\section{Introduction}

$\mathrm{OAB}$ is a common urinary dysfunction in both men and women, symptoms of which include urinary urgency, urinary frequency, nocturia, and urinary urge incontinence. $\mathrm{OAB}$ is estimated to occur in 33 million Americans or approximately $16.5 \%$ of the population [1-4]. In the longterm care setting, it is estimated that as many as half of all female residents suffer from incontinence [3, 4]. $\mathrm{OAB}$ is a serious medical and financial concern for several reasons. $\mathrm{OAB}$ is associated with medical and quality of life consequences that further compromise the health and well being of institutionalized and community-dwelling patients. Specifically, urinary incontinence (UI) has been associated with an increased risk of urinary tract infections, pressure ulcers, falls and fractures, which may severely compromise patient function and overall health [4-6]. Incontinence also consumes medical resources, staff, and provider time, which drives up the cost of care [6].

UI has been estimated to affect $20-33 \%$ of adults and greater percentages of the elderly [1-4]. UI is approximately twice as common among women than among men [5, 6]. Based on recent epidemiological studies, the overall prevalence of UI in women is $16.9 \%$, which translates into an estimated 17.5 million women in the United States who suffer from this condition [7]. Prevalence increases with age, from $4.8 \%$ in women under the age of 25 to $30.9 \%$ in those over the age of 65 [7]. Elderly women that are institutionalized have a significantly higher prevalence of UI than those living at home, which is one of the contributing factors to institutionalization $[1,4]$. Despite the high estimate of prevalence, however, it is believed that as many as $50 \%$ of all cases of UI may not be reported, and that individuals with UI do not always seek medical help [8-10]. 
UI has a substantial impact on physical and mental quality of life. The estimated total economic cost for UI was $\$ 19.5$ billion in 2000 [5]. When indirect costs such as lost wages and productivity are included, the annual cost of incontinence increases to more than $\$ 26$ billion, with institutional care accounting for more than 23\% (\$8.4 billion) [11]. In addition, the need for effective management strategies increases proportionally as the population ages and the proportion of elderly individuals aged 65 years and older increases.

The main symptom of OAB is urgency, or a sudden and compelling desire to pass urine which is difficult to defer [12]. Sometimes there is an involuntary leakage of urine with the feeling of urgency, which is called urge incontinence. The main complaints among individuals with $\mathrm{OAB}$ are the need to void too often during the day, and waking once or more per night to void [13]. In clinical practice, the need to void more than eight times during the day is considered daytime frequency, while waking from sleep more than once per night to void is considered nocturia.

Urgency and urge incontinence usually result from an involuntary increase in bladder pressure due to bladder smooth muscle over-activity during the filling phase of the micturition cycle. The pathophysiology of OAB remains unclear, but there are two widely accepted explanations. First, partial denervation of the detrusor muscle is believed to increase excitability secondary to changes in central nervous system (CNS) pathways that inhibit bladder activity [14]. Second, increased sensitivity of the sensory nerve endings in the bladder results in increased excitability of the detrusor muscle [14]. In either case, increased cholinergic stimulation of the detrusor occurs via postsynaptic muscarinic receptors [12].

The bladder contains both $\mathrm{M}_{2}$ and $\mathrm{M}_{3}$ subtypes of the muscarinic receptor. Even though the $\mathrm{M}_{2}$ subtype is more abundant, it is the $\mathrm{M}_{3}$ subtype that is mainly responsible for bladder contraction [15]. As a result, pharmacotherapy focuses mainly on the use of drugs with anticholinergic properties to block the parasympathetic acetycholine pathway and reduce the intensity of detrusor muscle contraction $[16,17]$. By partially blocking the binding of acetycholine to detrusor muscarinic receptors, anticholinergic agents reduce the level of stimulation via parasympathetic neural impulses. Through this mechanism, anticholinergic therapy increases bladder capacity and delays the initial urge to void, thereby reducing the symptoms of $\mathrm{OAB}[12]$. However, none of the current anticholinergic medications act specifically on muscarinic receptors in the bladder; they also act in other parts of the body, where they cause dry mouth, constipation, nausea, and other adverse effects.

Since $\mathrm{OAB}$ is a chronic condition, the goal in treatment is to reduce long-term health care costs, and increase quality of life (QOL) and patient satisfaction. In addition to antimuscarinic treatments, other current treatments for UI include behavioral modification, such as bladder training, fluid manipulation, scheduled toileting, pelvic muscle exercises, and surgical interventions. Often, pharmacological treatment and behavioral modification are combined $[11,18$, 19].
Behavioral therapies are currently recommended as a first line therapy in the treatment of UI [20, 21]. Behavioral interventions are usually relatively inexpensive and easy to implement, but their effectiveness depends chiefly on patient motivation and compliance [22]. Thus, this type of treatment requires a high level of motivation and encouragement. The advantages of behavioral methods are improved central control of bladder function, avoidance of the mortality and morbidity of surgery, and no adverse drug reactions.

When nonpharmacological interventions have failed, drug therapy is commonly employed [10]. Drug treatment continues to play an important role in the management of women with UI, although many of the agents used have not been subjected to controlled clinical trials [23]. Based on a review of clinical studies reported in the literature, it is clear that there is no ideal drug, and there is a critical need for improved pharmacotherapy [24]. Current pharmacological approaches to improving the treatment of UI include delayed release formulations of existing oral agents, new pharmaceutical agents with greater specificity/selectivity, and alternative routes of administration. New generation pharmacological treatments, such as extended release (ER) tolterodine and transdermal oxybutynin, provide better or comparable efficacy with fewer adverse drug events [25-27].

\section{Behavioral Therapies for Overactive Bladder and UI}

As mentioned, behavioral therapies are considered the mainstay of treatment for urinary incontinence because they are noninvasive and can be initiated at the primary care level. However, the role that behavioral therapies play in the treatment of $\mathrm{OAB}$ has not been well addressed in the literature. Behavioral interventions include pelvic floor muscle training (PFMT), bladder training, and lifestyle modification. Lifestyle modifications for the management of $\mathrm{OAB}$ include smoking cessation, caffeine reduction, reduced alcohol consumption, weight loss, and limiting fluid intake. Several clinical trials have shown evidence of a relationship between obesity and $\mathrm{OAB}$, suggesting that weight loss may significantly reduce episodes of urge incontinence [28-31].

There appears to be a dose-dependent relationship between caffeine and $\mathrm{OAB}$. Patients with high caffeine intake (>400 mg/day) were 2.4 times more likely to experience detrusor overactivity [32]. Limiting fluid intake may also reduce frequency/urgency in $\mathrm{OAB}$ and improve patient quality of life $[31,33]$.

PFMT is most commonly used as a treatment for stress UI. The impact of PFMT appears to be multifactorial. In addition to the reflex inhibition of involuntary detrusor contraction, PFMT may provide the physical ability to voluntary contract the external sphincter and regain bladder control $[34,35]$. Evidence to support the efficacy of PFMT for $\mathrm{OAB}$ is growing [36]. Patients with detrusor over activity who completed a PFMT program experienced a significant and clinically relevant reduction in daily UI episodes $[35,36]$. There was also a significant decrease in urge score, defined as 
the frequency of leakage ( $0=$ never to $4=$ always) during 9 activities that can trigger urge incontinence.

Bladder training (BT) involves a systematic voiding regimen to lengthen the interval between voids until an acceptable pattern has been restored. Bladder diaries are used to establish maximum baseline voiding intervals, which are progressively increased by 15 to 30 minutes as tolerated. BT has been used for patients with stress incontinence, detrusor overactivity, or mixed incontinence, and clinical studies have demonstrated the effectiveness of BT in relieving the symptoms of UI $[37,38]$. BT resulted in a significant reduction in UI episodes, including a significant decrease in volume of urine lost per UI episode. Despite this evidence of efficacy, however, the mechanism of BT's impact remains unclear, and there is little support for the common assertion that BT increases bladder capacity. McClish and coworkers reported a significant reduction in UI but no significant change in urodynamic parameters after 6 weeks of BT, while Else and colleagues found a significant increase in capacity at first sensation to void but not in maximum cystometric capacity $[39,40]$. Regardless of mechanism, these studies demonstrate the effectiveness of BT in reducing UI.

Although behavioral modification has proven to be effective in reducing the symptoms of UI and OAB, it is not considered a cure. In addition, there have been no headto-head trials of different behavioral interventions which would support one type over another. Increasingly, the emphasis in treatment of $\mathrm{OAB}$ is on combined behavioral and pharmacologic therapy.

\section{Pharmacotherapy for $\mathrm{OAB}$ and UI}

Anticholinergic drugs have been available for the treatment of $O A B$ for years and their use is widespread in clinical practice. The number of anticholinergics on the market is increasing, and their effectiveness has been assessed in many studies [41-45]. There are questions regarding the role of anticholinergics in different patient groups such as the elderly, men, women, and patients with comorbidities, as well as the best route of administration. Despite these uncertainties, anticholinergics are increasingly being used in primary and secondary settings, particularly for the treatment of urge incontinence [46].

The International Consultation on Incontinence recommends anticholinergics as a first line pharmacotherapy in urge incontinence for men, women, the elderly, and patients with neurogenic detrusor overactivity. The main disadvantage to the use of this class of drug is the side effect profile. Newer generation anticholinergic medications have fewer side effects as compared to the older generations, but dry mouth is still a common adverse effect reported in almost one third of patients receiving these drugs [47]. Also, there are few studies that report the long-term effectiveness of these drugs [17].

3.1. Oxybutynin. Oxybutynin is an anticholinergic agent that has antimuscarinic, antispasmodic, and potential local anesthetic effects $[48,49]$. It has been in widespread clinical use since 1975 and has been the most extensively studied in this class of drugs by clinicians. It is available in immediaterelease (Ditropan), extended-release (Ditropan XL), and transdermal (Oxytrol) forms. Oxybutynin has been shown to have a high affinity for muscarinic receptors in the bladder, with a higher affinity for $M_{1}$ and $M_{3}$ receptors than $M_{2}$ $[50,51]$. The effectiveness of different forms of oxybutynin in the management of patients with detrusor overactivity is well documented.

A 2007 study by Stohrere and colleagues found that immediate release (IR) oxybutynin increased maximum cytometric capacity from 164 to $298 \mathrm{~mL}$ and decreased maximum detrusor pressure from 68.6 to $43.1 \mathrm{~cm} \mathrm{H}_{2} \mathrm{O}$ in patients with detrusor overactivity [52]. A trial of extendedrelease oxybutynin (oxybutynin XL) showed that cystometric bladder capacity increased from 274 to $380 \mathrm{~mL}$ and incontinence episodes dropped from 13 to 6 per week, even though postvoid residual urine increased in patients treated with oxybutynin XL [53].

Oxybutynin XL has a less severe dry mouth side effect than oxybutynin IR and is more commonly used in practice [53]. In one study, the incidence of moderate to severe dry mouth in patients on oxybutynin XL was $23 \%$, with only $1.6 \%$ of patients discontinuing the medication due to adverse effects [54]. A follow-up study that evaluated oxybutynin XL in patients with comorbidities (spinal cord injury, multiple sclerosis, and Parkinsonism) confirmed the improvement in urodynamic parameters [55]. The latter study concluded that the administration of up to $30 \mathrm{mg}$ /day of oxybutynin XL was both efficacious and safe in these populations. Recently it was demonstrated that the use of oxybutynin XL in the elderly may impair recent memory [56].

In order to maximize efficacy and minimize adverse effects, an oxybutynin transdermal delivery system (oxybutynin-TDS) was recently developed and compared with oxybutynin XL. Oxybutynin-TDS increased cystomic capacity from $247 \mathrm{~mL}$ to $395 \mathrm{~mL}$, increased reflex volume from $190 \mathrm{~mL}$ to $249 \mathrm{~mL}$, and decreased maximum detrusor pressure from 61.2 to $37.8 \mathrm{~cm} \mathrm{H}_{2} \mathrm{O}$ [57]. A maximum dose of $11.7 \mathrm{mg}$ per day was found to be well tolerated by patients while improving continence. In a related study comparing oxybutynin-TDS to tolterodine, the most common side effect was application site reaction (14\%), and the incidence of dry mouth was reduced to $4.1 \%$ as compared to the tolterodine treatment group (7.3\%) [58].

3.2. Tolterodine. Tolterodine is a competitive muscarinic receptor antagonist with relative functional selectivity for bladder muscarinic receptors [59]. While the drug shows no specificity for receptor subtypes, it does appear to target the bladder over the salivary gland [60]. Tolterodine is available in immediate- and extended- release forms, and both formulations showed good efficacy for symptoms of $\mathrm{OAB}$ in a large study population [61]. However, extendedrelease is preferred by both clinicians and patients due to a less severe side effect profile [62]. In a randomized controlled study of tolterodine XL $4 \mathrm{mg}$ /day in patients with urge incontinence and urinary frequency, no differences were found in terms of efficacy, tolerability, or safety between older and younger patients [61]. 
A recent trial comparing tolterodine $\mathrm{XL}$ to tolterodine IR and placebo found tolterodine XL to be significantly more effective [63]. In addition to increased efficacy, tolterodine XL has been shown to have better tolerability. In a doubleblind, multicenter, randomized placebo controlled trial, tolterodine XL was found to be $18 \%$ more effective in reducing episodes of urge incontinence, with a 23\% lower incidence of dry mouth [64]. The efficacy of tolterodine XL was confirmed in several clinical trials, including the OPERA (Overactive bladder: Performance of Extended Release Agents), OBJECT (Overactive Bladder: Judging Effective Control and Treatment), and ACET (Antimuscarinic Clinical Effectiveness Trial) studies [65-67]. The safety of tolterodine has also been confirmed, and at the recommended daily dose, the incidence of adverse events was no different than placebo [68].

In a comparison of the safety and efficacy of tolterodine versus oxybutynin, clinical efficacy was similar for both drugs; however oxybutynin had higher withdrawal rates and a higher incidence of dry mouth $[45,69]$.

3.3. Trospium Chloride. Trospium is a smooth muscle relaxant that is nonselective for muscarinic receptor subtypes [70]. It is a quaternary ammonium compound that was recently approved by the US Food and Drug Administration (FDA) for the treatment of OAB [71]. Trospium was initially provided as a single $20 \mathrm{mg}$ dose for twice daily use; it has more recently been approved in a $60 \mathrm{mg}$ once daily formulation. In multiple efficacy trials in $\mathrm{OAB}$ patients, trospium produced significant improvements in maximum detrusor pressure, maximum cystometric capacity, and bladder volume at first involuntary contraction [72-75]. In a study testing double daily dosages of trospium chloride (90 $\mathrm{mg}$ ) in a mixed incontinence patient population that did not respond well with a standard dose, treatment with a double dose yielded improvements in reflex volume, cystometric capacity, and detrusor pressure as compared with a standard dose (45 mg) [73]. When an even higher dosage $(90 \mathrm{mg} /$ day) of trospium chloride was tested, it was reported that patients who were not responsive to the standard dose $(45 \mathrm{mg})$ could be safely treated with up to three times the dose of trospium/day [76]. Similar to solifenacin (see below), trospium chloride may have a lower risk of CNS side effects because of its lower predilection to cross the blood-brain barrier [77]. It also has the added benefit of being metabolized by the kidneys rather than the cytochrome P450 system, thereby having fewer interactions with other medications [77]. Thus, this therapy may be beneficial for patients who are elderly and/or receiving multiple medications.

Trospium has been compared to oxybutynin in a randomized, multicenter trial [78]. The trial found that with both agents, there was a significant increase in bladder capacity, a decrease in maximum voiding detrusor pressure and a significant increase in compliance as compared to placebo, although there were no statistically significant differences between the two treatment groups [78]. However, patients taking trospium had a lower incidence of dry mouth and were less likely to withdraw as compared to the oxybutynin group [78].

3.4. Solifenacin. Solifenacin is an antimuscarinic agent and a potent $M_{3}$ receptor antagonist that has selectivity for the $M_{3}$ over the $\mathrm{M}_{2}$ receptor [79]. It also has much higher potency against the $\mathrm{M}_{3}$ receptor in smooth muscle than it does against the $\mathrm{M}_{3}$ receptor in the salivary gland [79]. Solifenacin efficacy has been proven in multiple trials in OAB patients [80-82]. For instance, phase III studies with solifenacin (5 and $10 \mathrm{mg}$ ) consistently showed it to be more effective than placebo for all $\mathrm{OAB}$ variables measured [80]. A recent SUNRISE study showed that solifenacin was significantly more effective than placebo in reducing the mean number of episodes of severe urgency with or without incontinence per 24 hours, improved urgency as early as day 3 of treatment, and was well tolerated [83]. Importantly, in contrast to oxybutynin, it is postulated that solifenacin is very unlikely to cross the blood brain barrier due to its biochemistry, and no cognitive impairment associated with this drug has been reported [84].

In a direct comparison between solifenacin in 5 and $10 \mathrm{mg}$ doses and tolterodine XL in a randomized, doubleblind trial, solifenacin was at least as effective as tolterodine $\mathrm{XL}$ in reducing micturition frequency, and it was significantly more effective than tolterodine XL in improving most other $\mathrm{OAB}$ variables [81]. In a meta-analysis of seven placebocontrolled $\mathrm{OAB}$ studies, the mean and median reductions in the number of urgency episodes with solifenacin were greater than with several other agents such as oxybutynin, tolterodine, trospium, and darifenacin [85]. These studies suggest that solifenacin is an effective treatment for $\mathrm{OAB}$ with the most commonly reported adverse events being dry mouth, constipation, and blurred vision.

3.5. Darifenacin. Darifenacin is a highly selective $\mathrm{M}_{3}$ receptor antagonist that was approved in 2004 for the treatment of OAB. It has a fivefold higher affinity for the $\mathrm{M}_{3}$ receptor relative to the $M_{1}$ receptor [79]. This $M_{3}$-selective receptor antagonist is potentially more bladder-specific, with a reduced tendency for anticholinergic side effects [86]. Darifenacin is available in $7.5 \mathrm{mg} /$ day and $15 \mathrm{mg} /$ day formulations. The drug is associated with relatively high rates of constipation ( $14.4 \%$ for darifenacin $7.5 \mathrm{mg}$ daily) [87]. The efficacy of darifenacin has been investigated in several multicenter studies [88-91]. Darifenacin was significantly superior to placebo for improvements in micturition frequency, bladder capacity, frequency of urgency, severity of urgency, and number of incontinence episodes leading to a change in clothing or pads. In a comparison of darifenacin to oxybutynin, both drugs had similar efficacy; however, darifenacin had a less severe side effect profile than oxybutynin [92].

The most common adverse events associated with darifenacin are mild to moderate dry mouth and constipation, with a CNS and cardiac safety profile. Darifenacin has also been tested in patients who expressed dissatisfaction with prior OAB treatment with oxybutynin ER or tolterodine ER due to insufficient efficacy, tolerability problems, or both. 
TABLE 1: Impact of various interventions in $\mathrm{OAB}$ patients.

\begin{tabular}{ll}
\hline Intervention & Outcome \\
\hline Weight loss & $\begin{array}{l}\text { Obesity associated with OAB, moderate weight loss } \\
\text { associated with improvement in urge UI }\end{array}$ \\
Caffeine restriction & $\begin{array}{l}\text { Relationship between caffeine intake and OAB in } \\
\text { men/women not significant: impact of caffeine on OA } \\
\text { may be dose dependent }\end{array}$ \\
Fluid restriction & $\begin{array}{l}\text { Limiting fluid intake may reduce frequency/urgency } \\
\text { OAB, improve quality of life }\end{array}$ \\
Bladder training & $\begin{array}{l}\text { Used for patients with stress incontinence, detrusor } \\
\text { overactivity, or mixed incontinence: lengthen the } \\
\text { interval between voids, significant reduction in UI } \\
\text { episodes in 3-day bladder diaries, and significant } \\
\text { decrease in volume of urine lost }\end{array}$
\end{tabular}

References

[28-31]

Pelvic floor muscle training

Oxybutynin (immediate release, extended release, transdermal)

Tolterodine (immediate, extended-release forms)

Trospium chloride

Solifenacin

Darifenacin

Behavior and drug therapies of patient satisfaction, perceived improvement and reduction of bladder symptoms; anticholinergic may work synergistically with behavioral intervention because of the different mechanisms involved without incontinence per 24 hours and improving urgency at day 3 of treatment; improves most other $\mathrm{OAB}$ variables

Significantly superior to placebo for improving micturition frequency, bladder capacity, frequency of urgency, severity of urgency, and number of incontinence episodes leading to a change in clothing of daily UI frequency, night time significant reduction Increased maximum cytometric capacity and decreased

Increased maximum detrusor pressure, reflex volume, and less incidence of dry mouth compared to or pads; can be used for elderly population due to lower nervous system effects 
The results of this trial showed significant improvements in $\mathrm{OAB}$ symptoms with darifenacin [86]. Long-term studies have shown that there are high levels of persistence with darifenacin therapy and well-maintained treatment benefits (over 2 years in duration) [93, 99]. Darifenacin minimizes the risk of functional side effects due to blockade of other muscarinic subtypes, such as $\mathrm{M}_{1}$-mediated cognitive impairment [94]. This aspect of darifenacin therapy becomes important in the treatment of elderly populations who may be more susceptible to cognitive impairment and CNS effects. This patient population is at an increased risk of advanced age conditions such as diabetes, Alzheimer's, or multiple sclerosis. One analysis by Foote in patients aged 65 years or more found that darifenacin had a low incidence of nervous system effects (somnolence, dizziness), but showed a significant improvement in all OAB scores.

\section{Behavioral and Drug Therapy for OAB}

A combination of anticholinergic agents and behavioral interventions is a safe and effective first-line treatment for $\mathrm{OAB}[8,20,21,95]$. Most patients do not achieve complete continence with either therapy alone. In addition, longterm medication adherence can be difficult due to side effect profiles. Adding behavioral training to pharmacologic treatment is an appealing approach to improving outcomes and to possibly permitting discontinuation of drug therapy. Moreover, anticholinergics may work synergistically with behavioral intervention, due to the different mechanisms involved [96]. Many trials have shown the synergistic effect of these two interventions (Table 1).

The Mattiasson trial showed that a combination of tolterodine and BT significantly reduced void frequency and increased volume per void as compared to tolterodine alone [97]. Furthermore, $76 \%$ of the patients on tolterodine and BT reported an improvement in their bladder symptoms relative to baseline as compared with $71 \%$ in the tolterodine group [97]. This finding is consistent with a previous trial showing that BT significantly increases the efficacy of tolterodine for reducing voiding frequency and increasing volume voided [98].

Clinical data has also shown that combination therapy is associated with significantly fewer incontinent episodes, better quality of life, and greater treatment satisfaction as compared to nonpharmacologic intervention alone or drug treatment alone [100]. However, the effects of each of the 3 interventions were similar 3 months after treatment, suggesting that the nature of the treatment may not be as important as having a structured intervention program that includes education, counseling, and frequent monitoring of the treatment [100].

\section{Summary and Conclusions}

The choice of therapy for treating patients with $\mathrm{OAB}$ will be based on many factors, including prognosis of underlying disease, mental status, age, education, motivation, and mobility, and should be tailored to the individual.
A conservative management regime would begin with simple therapy (behavioral intervention) before proceeding to pharmacological treatment. Due to the complexities of the disease and individual variability, no single treatment for OAB exists. Rather, several treatments are typically begun and modified in order to meet the patient's desired therapeutic goal. The main goal in treating $\mathrm{OAB}$ is the preservation of upper urinary tract function and improvement of the patient's troubling urinary symptoms.

The prevalence of $\mathrm{OAB}$ is expected to increase in the future with the increasing number of elderly individuals in the population, emphasizing the need for methods to successfully manage OAB. Given the effectiveness of behavioral therapy, such as the absence of side effects, low cost, and ease of implementation in the outpatient setting, this approach is generally recommend as the first choice for $\mathrm{OAB}$ in the elderly.

The effectiveness of drug therapy and behavioral interventions for reducing urinary incontinence is well established [96-98, 100, 101]. There is strong evidence that a combination of approaches is useful in helping patients with $\mathrm{OAB}$ reduce incontinence episodes in certain settings. However, although combination therapy may be beneficial for reducing incontinence frequency during active treatment, a stepped approach, in which a single intervention is initiated first and then a second therapy is added for patients who do not achieve a satisfactory outcome, may be more practical and cost effective for optimal management of patients with $\mathrm{OAB}$.

\section{References}

[1] L. Hellstrom, P. Ekelund, I. Milsom, and D. Mellstrom, "The prevalenc of urinary incontinence and use of incontinence aids in 85-year-old men and women," Age and Ageing, vol. 19, no. 6, pp. 383-389, 1990.

[2] J. S. Brown, D. G. Seeley, J. Fong, D. M. Black, K. E. Ensrud, and D. Grady, "Urinary incontinence in older women: who is at risk?" Obstetrics and Gynecology, vol. 87, no. 5, part 1, pp. 715-721, 1996.

[3] E. A. Lagace, W. Hansen, and J. M. Hickner, "Prevalence and severity of urinary incontinence in ambulatory adults: an UPRNet study," Journal of Family Practice, vol. 36, no. 6, pp. 610-614, 1993.

[4] J. G. Ouslander, R. L. Kane, and I. B. Abrass, "Urinary incontinence in elderly nursing home patients," Journal of the American Medical Association, vol. 248, no. 10, pp. 11941198, 1982.

[5] L. Wilson, J. S. Brown, G. P. Shin, K. O. Luc, and L. L. Subak, "Annual direct cost of urinary incontinence," Obstetrics and Gynecology, vol. 98, no. 3, pp. 398-406, 2001.

[6] J. S. Brown, E. Vittinghoff, J. F. Wyman, et al., "Urinary incontinence: does it increase risk for falls and fractures? Study of Osteoporotic Fractures Research Group," Journal of the American Geriatrics Society, vol. 48, no. 7, pp. 721-725, 2000.

[7] R. R. Dmochowski, P. K. Sand, N. R. Zinner, et al., "Comparative efficacy and safety of transdermal oxybutynin and oral tolterodine versus placebo in previously treated patients with urge and mixed urinary incontinence," Urology, vol. 62, no. 2, pp. 237-242, 2003. 
[8] J. A. Fantl, D. K. Newman, J. Colling, et al., Urinary Incontinence in Adults: Acute and Chronic Management, Clinical Practice Guideline no. 2, Agency for Health Care Policy and Research, Rockville, Md, USA, 1996, AHCPR publication no. 96-0682.

[9] D. Thom, "Variation in estimates of urinary incontinence prevalence in the community: effects of differences in definition, population characteristics, and study type," Journal of the American Geriatrics Society, vol. 46, no. 4, pp. 473-480, 1998.

[10] K. L. Burgio, K. A. Matthews, and B. T. Engel, "Prevalence, incidence and correlates of urinary incontinence in healthy, middle-aged women," Journal of Urology, vol. 146, no. 5, pp. 1255-1259, 1991.

[11] T. W. Hu, T. H. Wagner, J. D. Bentkover, K. Leblanc, S. Z. Zhou, and T. Hunt, "Costs of urinary incontinence and overactive bladder in the United States: a comparative study," Urology, vol. 63, no. 3, pp. 461-465, 2004.

[12] Y. Homma, J. S. Paick, J. G. Lee, and K. Kawabe, "Clinical efficacy and tolerability of extended-release tolterodine and immediate-release oxybutynin in Japanese and Korean patients with an overactive bladder: a randomized, placebocontrolled trial," BJU International, vol. 92, no. 7, pp. 741747, 2003.

[13] C. J. Kelleher, L. D. Cardozo, V. Khullar, and S. Salvatore, "A medium term analysis of the subjective efficacy of treatment for women with detrusor instability and low bladder compliance," British Journal of Obstetrics and Gynaecology, vol. 104, no. 9, pp. 988-993, 1997.

[14] H. Hashim and P. Abrams, "Drug treatment of overactive bladder: efficacy, cost and quality-of-life considerations," Drugs, vol. 64, no. 15, pp. 1643-1656, 2004.

[15] K. E. Anderson, "Potential benefic of Muscarinic M3 receptor selectivity," European Urology Supplements, vol. 1, no. 4, pp. 23-28, 2002.

[16] K. Hesch, "Agents for treatment of overactive bladder: a therapeutic class review," Baylor University Medical Center Proceedings, vol. 20, no. 3, pp. 307-314, 2007.

[17] J. R. A. Duckett, S. Hall, and A. Woodward, "A medium term analysis of the subjective efficacy of treatment for women with detrusor instability and low bladder compliance," British Journal of Obstetrics and Gynaecology, vol. 105, no. 12, p. 1337, 1998.

[18] C. Hampel, D. Wienhold, N. Benken, C. Eggersmann, and J. W. Thüroff, "Definition of overactive bladder and epidemiology of urinary incontinence," Urology, vol. 50, no. 6, supplement 1, pp. 4-14, 1997.

[19] J. A. Couture and L. Valiquette, "Urinary incontinence," Annals of Pharmacotherapy, vol. 34, no. 5, pp. 646-655, 2000.

[20] E. A. Gormley, "Biofeedback and behavioral therapy for the management of female urinary incontinence," Urologic Clinics of North America, vol. 29, no. 3, pp. 551-557, 2002.

[21] J. L. Milne and K. N. Moore, "Factors impacting self-care for urinary incontinence," Urologic Nursing, vol. 26, no. 1, pp. 41-51, 2006.

[22] D. Marcell, S. Ransel, M. Schiau, and E. G. Duffy, "Treatment option alleviates female urge incontinence," The Nurse Practitioner, vol. 28, pp. 48-54, 2003.

[23] W. F. Stewart, J. B. Van Rooyen, G. W. Cundiff, et al., "Prevalence and burden of overactive bladder in the United States," World Journal of Urology, vol. 20, no. 6, pp. 327-336, 2003.
[24] J. M. Vapnek, "Urinary incontinence: screening and treatment of urinary dysfunction," Geriatrics, vol. 56, no. 10, pp. 25-29, 2001.

[25] R. M. O'Conor, M. Johannesson, S. L. Hass, and G. KobeltNguyen, "Urge incontinence: quality of life and patients' valuation of symptom reduction," PharmacoEconomics, vol. 14, no. 5, pp. 531-539, 1998.

[26] P. Van Kerrebroeck, K. Kreder, U. Jonas, N. Zinner, and A. Wein, "Tolterodine once-daily: superior efficacy and tolerability in the treatment of the overactive bladder," Urology, vol. 57, no. 3, pp. 414-421, 2001.

[27] M. A. Harvey, K. Baker, and G. A. Wells, "Tolterodine vs. oxybutynin in the treatment of urge UI: a meta-analysis," American Journal of Obstetrics \& Gynecology, vol. 185, pp. 56$61,2001$.

[28] H. M. Dallosso, R. J. Matthews, C. W. McGrother, M. M. K. Donaldson, and C. Shaw, "The association of diet and other lifestyle factors with the onset of overactive bladder: a longitudinal study in men," Public Health Nutrition, vol. 7, no. 7, pp. 885-891, 2004.

[29] L. L. Subak, E. Whitcomb, H. Shen, J. Saxton, E. Vittinghoff, and J. S. Brown, "Weight loss: a novel and effective treatment for urinary incontinence," Journal of Urology, vol. 174, no. 1, pp. 190-195, 2005.

[30] M. J. Dickson, "Nonsurgical treatment of stress urinary incontinence," BJOG, vol. 115, no. 8, pp. 1062-1063, 2008.

[31] J. L. Milne, "Behavioral therapies for overactive bladder: making sense of the evidence," Journal of Wound, Ostomy and Continence Nursing, vol. 35, no. 1, pp. 93-101, 2008.

[32] L. A. Arya, D. L. Myers, and N. D. Jackson, "Dietary caffeine intake and the risk for detrusor instability: a case-control study," Obstetrics and Gynecology, vol. 96, no. 1, pp. 85-89, 2000.

[33] L. Swithinbank, H. Hashim, and P. Abrams, "The effect of fluid intake on urinary symptoms in women," Journal of Urology, vol. 174, no. 1, pp. 187-189, 2005.

[34] A. Shafik and I. A. Shafik, "Overactive bladder inhibition in response to pelvic floor muscle exercises," World Journal of Urology, vol. 20, no. 6, pp. 374-377, 2003.

[35] K. Bø and L. C. M. Berghmans, "Nonpharmacologic treatments for overactive bladder-pelvic floor exercises," Urology, vol. 55, no. 5, supplement 1, pp. 7-11, 2000.

[36] I. E. Nygaard, K. J. Kreder, M. M. Lepic, K. A. Fountain, and A. T. Rhomberg, "Efficacy of pelvic floor muscle exercises in women with stress, urge, and mixed urinary incontinence," American Journal of Obstetrics and Gynecology, vol. 174, no. 1, part 1, pp. 120-125, 1996.

[37] J. A. Fantl, J. F. Wyman, D. K. McClish, et al., "Efficacy of bladder training in older women with urinary incontinence," Journal of the American Medical Association, vol. 265, no. 5, pp. 609-613, 1991.

[38] L. L. Subak, C. P. Quesenberry Jr., S. F. Posner, E. Cattolica, and K. Soghikian, "The effect of behavioral therapy on urinary incontinence: a randomized controlled trial," Obstetrics and Gynecology, vol. 100, no. 1, pp. 72-78, 2002.

[39] D. K. McClish, J. A. Fantl, J. F. Wyman, G. Pisani, and R. C. Bump, "Bladder training in older women with urinary incontinence: relationship between outcome and changes in urodynamic observations," Obstetrics and Gynecology, vol. 77, no. 2, pp. 281-286, 1991.

[40] D. M. Elser, J. F. Wyman, D. K. McClish, et al., "The effect of bladder training, pelvic floor muscle training, or combination training on urodynamic parameters in women with 
urinary incontinence," Neurourology and Urodynamics, vol. 18, no. 5, pp. 427-436, 1999.

[41] S. Salvatore, M. Serati, and P. Bolis, "Tolterodine for the treatment of overactive bladder," Expert Opinion on Pharmacotherapy, vol. 9, no. 7, pp. 1249-1255, 2008.

[42] K. E. Andersson, "The overactive bladder: pharmacologic basis of drug treatment," Urology, vol. 50, no. 6A, supplement, pp. 74-79, 1997.

[43] U. Jonas, K. Höfner, H. Madersbacher, and T. H. Holmdahl, "Efficacy and safety of two doses of tolterodine versus placebo in patients with detrusor overactivity and symptoms of frequency, urge incontinence, and urgency: urodynamic evaluation. The International Study Group," World Journal of Urology, vol. 15, no. 2, pp. 144-151, 1997.

[44] R. Millard, J. Tuttle, K. Moore, et al., "Clinical efficacy and safety of tolterodine compared to placebo in detrusor overactivity," Journal of Urology, vol. 161, no. 5, pp. 15511555, 1999.

[45] R. A. Appell, "Clinical efficacy and safety of tolterodine in the treatment of overactive bladder: a pooled analysis," Urology, vol. 50, no. 6, supplement 1, pp. 90-99, 1997.

[46] G. Kobelt, "Economic considerations and outcome measurement in urge incontinence," Urology, vol. 50, no. 6, supplement 1, pp. 100-107, 1997.

[47] G. Nabi, J. D. Cody, G. Ellis, P. Herbison, and J. HaySmith, "Anticholinergic drugs versus placebo for overactive bladder syndrome in adults," Cochrane Database of Systematic Reviews, no. 4, Article ID CD003781, 2006.

[48] K. Waldeck, B. Larson, and K. E. Andersson, "Comparison of oxybutynin and it's active metabolite, N-desmethyloxybutynin, in the human detrusor and parotid gland," The Journal of Urology, vol. 157, pp. 1093-1097, 1997.

[49] K. M. Hughes, J. C. T. Lang, R. Lazare, et al., "Measurement of oxybutynin and its $\mathrm{N}$-desethyl metabolite in plasma, and its application to pharmacokinetic studies in young, elderly and frail elderly volunteers," Xenobiotica, vol. 22, no. 7, pp. 859-869, 1992.

[50] K. M. Hughes, J. C. T. Lang, R. Lazare, et al., "Measurement of oxybutynin and its $\mathrm{N}$-desethyl metabolite in plasma, and its application to pharmacokinetic studies in young, elderly and frail elderly volunteers," Xenobiotica, vol. 22, no. 7, pp. 859-869, 1992.

[51] L. Nilvebrant and B. Sparf, "Dicyclomine, benzhexol, and oxybutynine distinguish between subclasses of muscarinic binding sites," European Journal of Pharmacology, vol. 123, no. 1, pp. 133-143, 1986.

[52] M. Stöhrer, G. Mürtz, G. Kramer, F. Schnabel, E. P. Arnold, and J.-J. Wyndaele, "Propiverine compared to oxybutynin in neurogenic detrusor overactivity_results of a randomized, double-blind, multicenter clinical study," European Urology, vol. 51, no. 1, pp. 235-242, 2007.

[53] M. O'Leary, J. R. Erickson, C. P. Smith, C. McDermott, J. Horton, and M. B. Chancellor, "Effect of controlled-release oxybutynin on neurogenic bladder function in spinal cord injury," Journal of Spinal Cord Medicine, vol. 26, no. 2, pp. 159-162, 2003.

[54] D. M. Gleason, J. Susset, C. White, D. R. Munoz, and P. K. Sand, "Evaluation of a new once-daily formulation of oxybutynin for the treatment of urinary urge incontinence. Ditropan XL Study Group," Urology, vol. 54, no. 3, pp. 420 423, 1999.

[55] N. Bennett, M. O’Leary, A. S. Patel, M. Xavier, J. R. Erickson, and M. B. Chancellor, "Can higher doses of oxybutynin improve efficacy in neurogenic bladder?" Journal of Urology, vol. 171, no. 2, part 1, pp. 749-751, 2004.

[56] G. Kay, K. Kardiasmenos, and T. Crook, "Differential effects of the antimuscarinic agents tolterodine tartarate ER and oxybutynin chloride ER on recent momory in older subjects," in Proceedings of the Annual Meeting of the International Continence Society, Christchurch, New Zealand, 2006.

[57] M. K. Kennelly, G. Lemack, J. Foote, and C. Trop, "Transdermal-oxybutynin improves continence and urodynamics in neurogenic bladder after spinal cord injury," The Journal of Spinal Cord Medicine, vol. 30, p. 395, 2007.

[58] R. R. Dmochowski, P. K. Sand, and N. R. Zinner, "Comparative efficacy and safety of transdermal oxybutynin and oral tolterodine versus placebo in previously treated patients with urge and mixed urinary incontinence," Urology, vol. 62, pp. 237-242, 2003.

[59] S. Salvatore, M. Serati, and P. Bolis, "Tolterodine for the treatment of overactive bladder," Expert Opinion on Pharmacotherapy, vol. 9, no. 7, pp. 1249-1255, 2008.

[60] L. Nilvebrant, K.-E. Andersson, P.-G. Gillberg, M. Stahl, and B. Sparf, "Tolterodine-a new bladder-selective antimuscarinic agent," European Journal of Pharmacology, vol. 327, no. 2-3, pp. 195-207, 1997.

[61] M.-S. Choo, C. K. Doo, and K.-S. Lee, "Satisfaction with tolterodine: assessing symptom-specific patient-reported goal achievement in the treatment of overactive bladder in female patients (STARGATE study)," International Journal of Clinical Practice, vol. 62, no. 2, pp. 191-196, 2008.

[62] L. Nilvebrant, B. Hallén, and G. Larsson, "Tolterodinea new bladder selective muscarinic receptor antagonist: preclinical pharmacological and clinical data," Life Sciences, vol. 60, no. 13-14, pp. 1129-1136, 1997.

[63] S. Swift, A. Garely, T. Dimpfl, and C. Payne, "A new oncedaily formulation of tolterodine provides superior efficacy and is well tolerated in women with overactive bladder," International Urogynecology Journal and Pelvic Floor Dysfunction, vol. 14, no. 1, pp. 50-55, 2003.

[64] P. Van Kerrebroeck, K. Kreder, U. Jonas, N. Zinner, and A. Wein, "Tolterodine once-daily: superior efficacy and tolerability in the treatment of the overactive bladder," Urology, vol. 57, no. 3, pp. 414-421, 2001.

[65] A. C. Diokno, R. A. Appell, P. K. Sand, et al., "Prospective, randomized, double-blind study of the efficacy and tolerability of the extended-release formulations of oxybutynin and tolterodine for overactive bladder: results of the OPERA trial," Mayo Clinic Proceedings, vol. 78, no. 6, pp. 687-695, 2003.

[66] R. A. Appell, P. Sand, R. Dmochowski, R. Anderson, and N. Zinner, "Prospective randomized controlled trial of extended-release oxybutynin chloride and tolterodine tartrate in the treatment of overactive bladder: results of the OBJECT study," Mayo Clinic Proceedings, vol. 76, no. 4, pp. 358-363, 2001.

[67] D. Sussman and A. Garely, "Treatment of overactive bladder with once-daily extended-release tolterodine or oxybutynin: the Antimuscarinic Clinical Effectiveness Trial (ACET)," Current Medical Research and Opinion, vol. 18, no. 4, pp. 177184, 2002.

[68] L. Rentzhog, S. L. Stanton, L. Cardozo, E. Nelson, M. Fall, and P. Abrams, "Efficacy and safety of tolterodine in patients with detrusor instability: a dose-ranging study," British Journal of Urology, vol. 81, no. 1, pp. 42-48, 1998.

[69] P. Abrams, R. Freeman, C. Anderstrom, and A. Mattiasson, "Tolterodine, a new antimuscarinic agent: as effective but 
better tolerated than oxybutynin in patients with an overactive bladder," British Journal of Urology, vol. 81, no. 6, pp. 801-810, 1998.

[70] G. Schladitz-Keil, H. Spahn, and E. Mutschler, "Determination of bioavailability of the quaternary ammonium compound trospium chloride in man from urinary excretion data," Arzneimittel Forschung, vol. 36, pp. 984-987, 1986.

[71] D. Staskin, P. Sand, N. Zinner, and R. Dmochowski, “Once daily trospium chloride is effective and well tolerated for the treatment of overactive bladder: results from a multicenter phase III trial," Journal of Urology, vol. 178, no. 3, pp. 978984, 2007.

[72] I. Füsgen and D. Hauri, "Trospium chloride: an effective option for medical treatment of bladder over-activity," International Journal of Clinical Pharmacology and Therapeutic Toxicology, vol. 38, pp. 223-234, 2000.

[73] M. Horstmann, T. Schaefer, Y. Aguilar, A. Stenzl, and K. D. Sievert, "Neurogenic bladder treatment by doubling the recommended antimuscarinic dosage," Neurourology and Urodynamics, vol. 25, no. 5, pp. 441-445, 2006.

[74] M. Stohrere, P. Bauer, B. M. Giannetti, et al., "Effect of trospium chloride on urodynamic parameter in patients with detrusor hyperreflexia due to spinal cord injuries. A multicenter placebo-controlled double-blind trial," Urologia Internationalis, vol. 47, pp. 138-143, 1991.

[75] L. Cardozo, C. R. Chapple, P. Toozs-Hobson, et al., "Efficacy of trospium chloride in patients with detrusor instability: a placebo-controlled, randomized, double-blind, multicentre clinical trial," BJU International, vol. 85, no. 6, pp. 659-664, 2000.

[76] M. Menarini, G. Del Popolo, P. Di Benedetto, et al., "Trospium chloride in patients with neurogenic detrusor overactivity: is dose titration of benefit to the patients?" International Journal of Clinical Pharmacology and Therapeutics, vol. 44, no. 12, pp. 623-632, 2006.

[77] H. Madersbacher, M. Stoher, R. Richter, et al., "Trospium chloride versus oxybutynin: a randomized, double-blind, multicentre trial in the treatment of detrusor hyperreflexia," British Journal of Urology, vol. 75, pp. 452-456, 1995.

[78] V. A. Alabaster, "Discovery and development of selective M3 antagonists for clinical use," Life Sciences, vol. 60, no. 13-14, pp. 1053-1060, 1997.

[79] C. R. Chapple, L. Cardozo, W. D. Steers, and F. E. Govier, "Solifenacin significantly improves all symptoms of overactive bladder syndrome," International Journal of Clinical Practice, vol. 60, no. 8, pp. 959-966, 2006.

[80] C. R. Chapple, R. Martinez-Garcia, L. Selvaggi, et al., "A comparison of the efficacy and tolerability of solifenacin succinate and extended release tolterodine at treating overactive bladder syndrome: results of the STAR trial," European Urology, vol. 48, no. 3, pp. 464-470, 2005.

[81] L. Cardozo, M. Lisec, R. Millard, et al., "Randomized, double-blind placebo controlled trial of the once daily antimuscarinic agent solifenacin succinate in patients with overactive bladder," Journal of Urology, vol. 172, no. 5, part 1, pp. 1919-1924, 2004.

[82] L. Cardozo, E. Hessdorfer, R. Milani, et al., "Solifenacin in the treatment of urgency and other symptoms of overactive bladder: results from a randomized, double-blind, placebocontrolled, rising-dose trial," BJU International, vol. 102, no. 9, pp. 1120-1127, 2008.

[83] G. Kay, T. Crook, L. Rekeda, et al., "Differential effects of the antimuscarinic agents darifenacin and oxybutynin ER on memory in older subjects," European Urology, vol. 50, no. 2, pp. 317-326, 2006.

[84] M. C. Michel and J. J. M. C. H. de la Rosette, "Role of muscarinic receptor antagonists in urgency and nocturia," BJU International, vol. 96, supplement 1, pp. 37-42, 2005.

[85] D. R. P. Guay, "Clinical pharmacokinetics of drugs used to treat urge incontinence," Clinical Pharmacokinetics, vol. 42, no. 14, pp. 1243-1285, 2003.

[86] N. Zinner, K. C. Kobashi, U. Ebinger, et al., "Darifenacin treatment for overactive bladder in patients who expressed dissatisfaction with prior extended-release antimuscarinic therapy," International Journal of Clinical Practice, vol. 62, no. 11, pp. 1664-1674, 2008.

[87] "Solifenacin and darifenacin for overactive bladder," Obstetrics \& Gynecology, vol. 106, no. 2, pp. 401-402, 2005.

[88] F. Haab, L. Stewart, and P. Dwyer, "Darifenacin, an M3 selective receptor antagonist, is an effective and well-tolerated once-daily treatment for overactive bladder," European Urology, vol. 45, no. 4, pp. 420-429, 2004.

[89] C. R. Chapple, "Darifenacin is well tolerated and provide significant improvement in the symptoms of overactive bladder: a pooled analysis of phase III studies," The Journal of Urology, vol. 171, supplement, p. 130, 2004, abstract no. 487.

[90] A. Wagg, J. J. Wyndaele, and P. Sieber, "Efficacy and tolerability of solifenacin in elderly subjects with overactive bladder syndrome: a pooled analysis," The American Journal of Geriatric Pharmacotherapy, vol. 4, no. 1, pp. 14-24, 2006.

[91] M. B. Chancellor and F. de Miguel, "Treatment of overactive bladder: selective use of anticholinergic agents with low drugdrug interaction potential," Geriatrics, vol. 62, no. 5, pp. 1524, 2007.

[92] C. R. Chapple and P. Abrams, "Comparison of darifenacin and oxybutynin in patients with overactive bladder: assessment of ambulatory urodynamics and impact on salivary flow," European Urology, vol. 48, no. 1, pp. 102-109, 2005.

[93] S. Hill, M. Elhilali, R. J. Millard, et al., "Long-term darifenacin treatment for overactive bladder in patients aged 65 years and older: analysis of results from a 2-year, open-label extension study," Current Medical Research and Opinion, vol. 23, no. 11, pp. 2697-2704, 2007.

[94] J. Foote, K. Glavind, G. Kralidis, and J.-J. Wyndaele, "Treatment of overactive bladder in the older patient: pooled analysis of three phase III studies of darifenacin, an M3 selective receptor antagonist," European Urology, vol. 48, no. 3, pp. 471-477, 2005.

[95] K. E. Anderson, "Antimuscarinics for treatment of overactive bladder," The Lancet Neurology, vol. 3, no. 1, pp. 46-53, 2004.

[96] P. S. Goode, K. L. Burgio, J. L. Locher, M. G. Umlauf, L. K. Lloyd, and D. L. Roth, "Urodynamic changes associated with behavioral and drug treatment of urge incontinence in older women," Journal of the American Geriatrics Society, vol. 50, no. 5, pp. 808-816, 2002.

[97] A. Mattiasson, J. Blaakaer, K. Hoye, and A. J. Wein, "Simplified bladder training augments the effectiveness of tolterodine in patients with an over-active bladder," British Journal of Urology International, vol. 91, pp. 154-160, 2003.

[98] K. L. Burgio, P. S. Goode, J. L. Locher, et al., "Behavioral training with and without biofeedback in the treatment of urge incontinence in older women: a randomized controlled trial," Journal of the American Medical Association, vol. 288, no. 18, pp. 2293-2299, 2002. 
[99] F. Haab, J. Corcos, P. Siami, et al., "Long-term treatment with darifenacin for overactive bladder: results of a 2-year, openlabel extension study," BJU International, vol. 98, no. 5, pp. 1025-1032, 2006.

[100] J. F. Wyman, J. A. Fantl, D. K. McClish, and R. C. Bump, "Comparative efficacy of behavioral interventions in the management of female urinary incontinence," American Journal of Obstetrics and Gynecology, vol. 179, no. 4, pp. 9991007, 1998.

[101] C. G. Klutke, K. L. Burgio, J. F. Wyman, et al., "Combined effects of behavioral intervention and tolterodine in patients dissatisfied with overactive bladder medication," Journal of Urology, vol. 181, no. 6, pp. 2599-2607, 2009. 


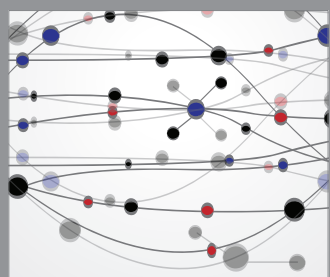

The Scientific World Journal
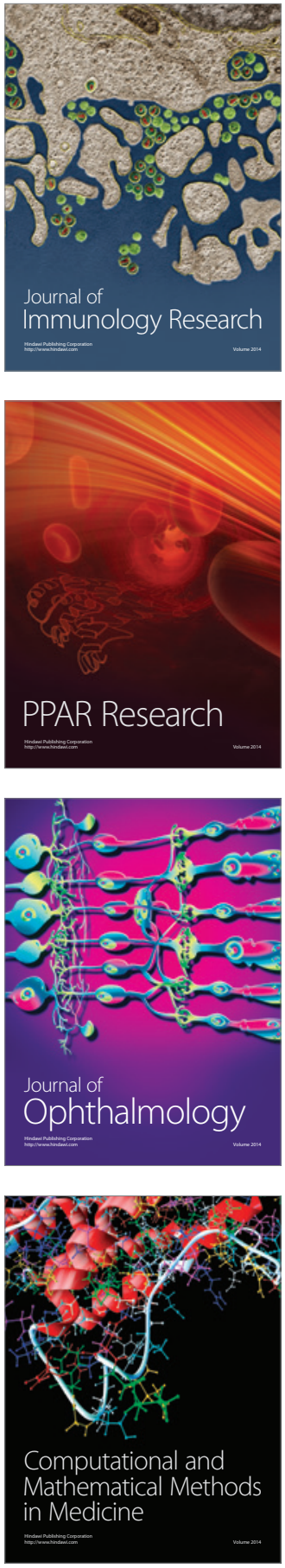

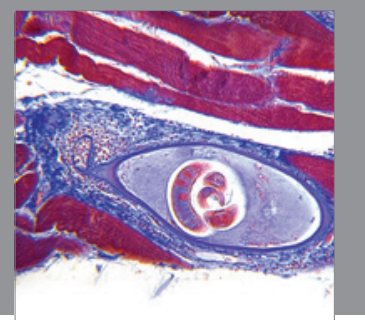

Gastroenterology

Research and Practice
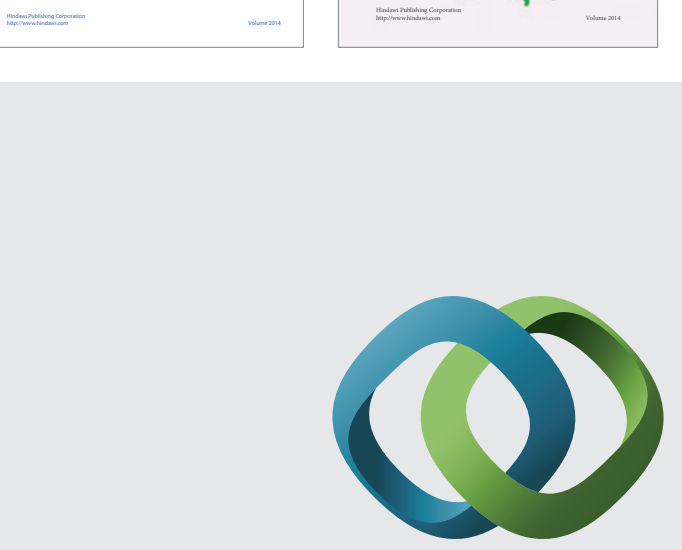

\section{Hindawi}

Submit your manuscripts at

http://www.hindawi.com
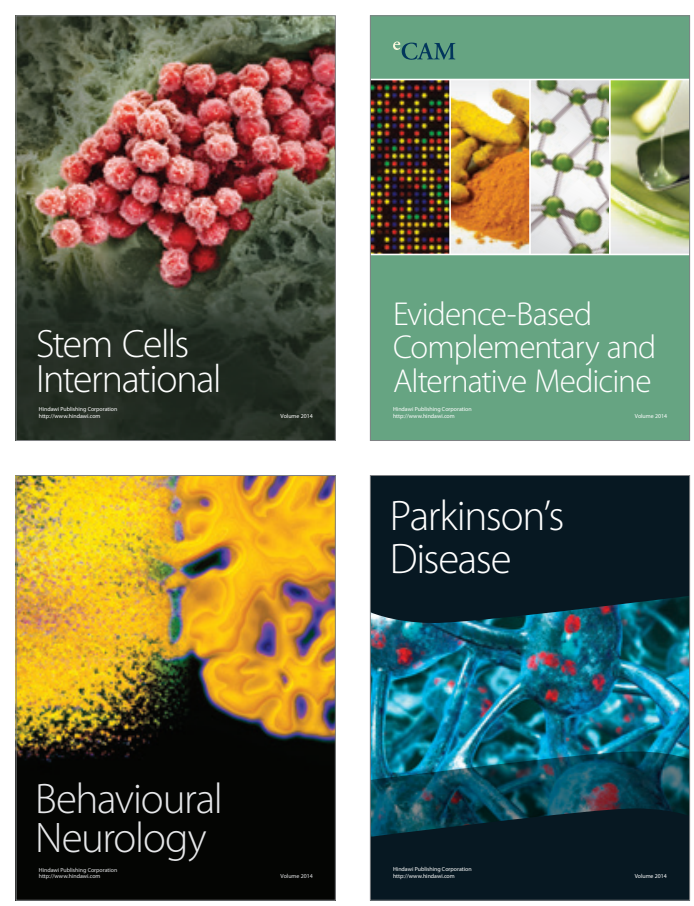

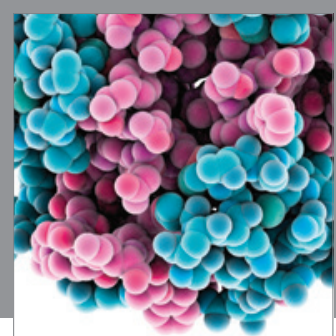

Journal of
Diabetes Research

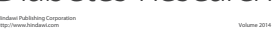

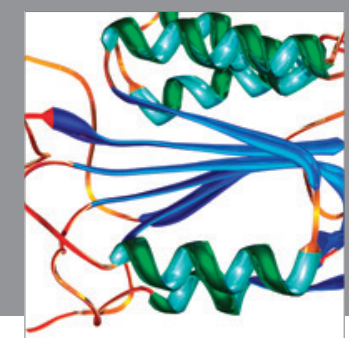

Disease Markers
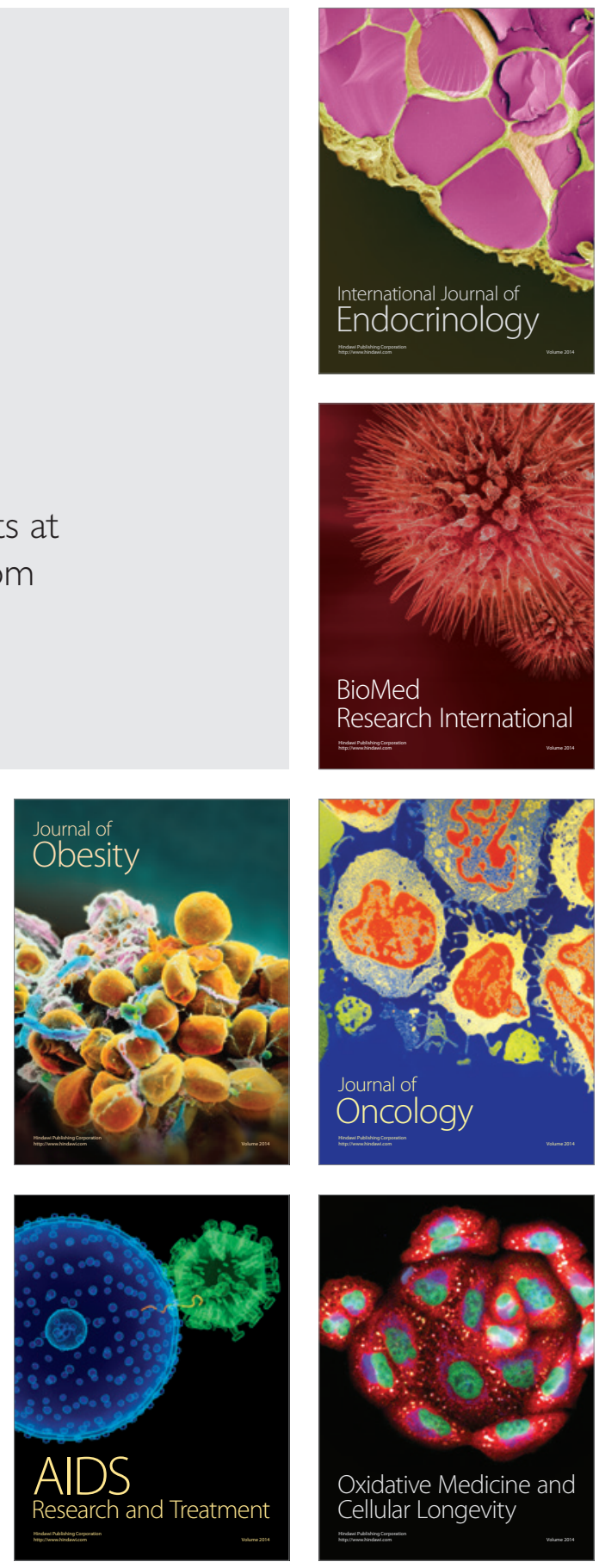